\title{
Are Modern Fruit Production Systems Sustainable?
}

Ian A. Merwin ${ }^{1}$ and Marvin P. Pritts ${ }^{2}$

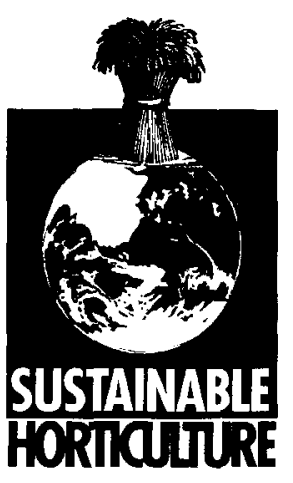

$\Gamma$

he quality, diversity, and availability of fruits is greater today than at any time in recorded history. Relative wholesale values of most fruits have been stable or declining for decades, higher crop

yields are produced on decreasing acreage, and postharvest storage and quality have improved as new technologies have been developed (NRC, 1989). Americans now spend only $12 \%$ of their personal income on food-the lowest proportional expenditure of any industrialized nation. Contemporary fruit growers are more likely to worry about excess production and consequent depression of wholesale prices than crop failures or insufficient supply. Surprisingly, amidst these achievements, there are also increasing doubts about our ability to sustain current production and availability of fruits and other crops. "Sustainability" has emerged as a new paradigm by which fruit production systems and practices are judged (York, 1991). Federal and private funding agencies are reallocating millions of dollars from traditional research into new programs assessing environmental impacts, food safety, and other aspects of agricultural sustainability Are these recent trends an over-reaction to subjective and misinformed public attitudes toward a successful and sustainable agriculture, or are modern fruit production systems flawed and nonsustainable? We try to answer these questions here by discussing sustainability in the context of perennial crops, estimating the present and future availability of essential resources for fruit production, and surveying trends that are likely to affect future fruit crop production. 
Criteria for sustainability. The recent emphasis on sustainability originated within international development agencies as a criterion for evaluating the progress and performance of socioeconomic development programs. It was extended subsequently to agriculture in the developed nations, and a myriad of different and often contradictory definitions of sustainability have since been proposed (Crews et al., 1992). Most agree that sustainable farming systems all share certain attributes. First, they conserve and protect the essential agroecosystem resource bases (e.g., soils, water, genetic diversity). Second, they provide adequate quantity and quality of the food and fiber to meet present and future requirements. Third, they optimize crop output per unit of capital, labor, land, or energy input. Finally, they are profitable enough to provide farmers with adequate living standards and support viable rural communities. Beyond these four basic attributes, there is little agreement about the best definition of sustainability, and we do not intend to contribute further to that controversy.

\section{Fruit production systems}

Traditional fruit growing and gathering system. At first glance, traditional fruit production systems appear to provide excellent models of sustainability. They were developed with minimal external inputs, and obviously they have endured for very long periods of time. There are groves where avocado, cashew, olive, apple, grapes, and other perennial fruits have been harvested continuously for many centuries (Simmonds, 1976). A substantial portion of the world's production of several commercially important tropical fruits (e.g., Brazil nuts) still is harvested from semidomesticated, old forest stands (Smith et al., 1992). Many more fruits gathered in these agroforestry systems are not commercially marketed, but provide an essential part of the dietary needs of subsistence farmers and indigenous peoples. These traditional fruit production systems are certainly sustainable on their own merits. Nonetheless, rampant deforestation of large tracts for timber, grazing, and conversion to export cash crops threatens these forests, the local people who depend on them for food and income, and the invaluable diversity of flora and fauna that they harbor. In addition, these gathering systems often do not meet the food demands of increasing human populations.

If the clear cutting and conversion of tropical forests to pasture or field crops is necessary to provide adequate food for the people of Third-world countries, then traditional forest agroecosystems are nonsus- tainable. However, several studies have indicated that the long-term food and income yields of tropical forests used by low-impact gathering of fruits, nuts, latex, and other resources could surpass the short-term yields of timber or slash-and-burn crops that usually motivate deforestations (Smith et al., 1992). In such cases, it is perhaps the underlying socioeconomic systems that are nonsustainable, not the fruit production systems themselves. This fundamental distinction often is ignored. In many instances, farming systems are faulted for shortcomings that are caused not by the internal dynamics or integrity of the agroecosystem, but by external socioeconomic forces resulting from national policies. It is difficult for farmers to sacrifice voluntarily short-term gains for the sake of intangible future benefits when the cultural, commercial, and political systems in which they must survive are rewarding short-term profits and economies of scale. Traditional fruit and nut gathering systems-however intrinsically sustainable they may be-are threatened and losing ground everywhere because of external factors unrelated to the agroecological integrity of these venerable systems. Without changes in human population dynamics and local/global economic systems, it appears unlikely that many traditional fruit-growing systems can be sustainable.

Traditional family farm fruit production. The orchards, vineyards, and berry plantings of 75 years ago were usually just one component of diversified family operated farms. Diversified farms provided some important advantages to growers, insulating them from occasional crop failures and commodity price fluctuations. Smaller plantings and larger families reduced the need for hired help. Integrating livestock with field and fruit crop systems minimized certain off-farm inputs. Organic manures were readily available, and pest-infested fruit could be used for animal feed. On the other hand, the productivity of traditional orchards was generally low, and production/replacement cycles were considerably longer than they are today. Expertise, equipment, and technical support often were limiting. Fruit plantings consisted of many genotypes and were not grafted on clonal rootstocks, resulting in nonuniform crop stands that were difficult to manage. Nursery stock was propagated without regard for virus status, and diseased stock severely limited the production of many fruit crops. Pest controls included heavy-metal derivatives such as lead arsenate, or genetic sources of resistance (if they existed). The minor portion of each fruit harvest suitable for fresh consumption was bartered or marketed locally, was relatively expensive, and
"Traditional
fruit and nut
gathering
systems-however
intrinsically
sustainable they
may be-are
threatened and
losing ground
everywhere..." 
"Certain aspects of current intensive production and marketing systems are probably not sustainable in their present form ..." was available only during a limited season each year.

Modern commercial fruit production. Modern production systems differ in many ways from traditional systems. They require more capital to establish, and must be more precocious and productive to be profitable. Fruit trees are usually grafted onto sizereducing clonal rootstocks and planted at much greater densities. The harvest index is substantially higher in these "dwarf" orchards; they require less pesticide per acre, and they are easier and safer to prune and harvest because workers do not need to climb ladders. Similar changes have occurred in berry fruit production. For example, most strawberries are now grown in annual production systems. The major cultivars are cloned or micropropagated, with fewer genotypes suitable for commercial growers dependent on a few varieties of one crop for specialized markets. Intercrops and polycultures are rare, at least in the industrialized nations. Many of the traditional local varieties or landraces have been replaced by newer cultivars originating from scientific breeding programs. Pest control is accomplished through synthetic chemicals and breeding of resistant or tolerant cultivars. For the 20-odd major economic fruits that are bought and sold internationally, grading standards are high and market competition is fierce. Tropical fruits are consumed increasingly by people in temperate climate areas, and vice versa. Consumers in developed nations are offered an astounding diversity of relatively inexpensive, highquality fresh produce that is available yearround from growers throughout the world.

Changing consumer demands, coupled with stringent soil and climatic requirements, mandate that today's fruit plantings be reestablished continuously in the regions where growing conditions are optimal. The ability to replant fruits successfully in these sites without extensive modification is itself a good test of the sustainability of prior production practices. In commercial situations today, severe replant problems sometimes develop in previously productive orchards, vineyards, and berry plantations. Correction of nutrient deficiencies and/or soil physical problems such as drainage or compaction will sometimes solve these replant problems, but, in other situations, soil fumigation with broadspectrum biocides such as methyl bromide is necessary to maintain previous levels of production (Mai and Abiwi, 1981). With the recent loss of registration for most soil fumigants, it is questionable whether some fruit production centers can be sustained unless effective substitutes are developed (Merwin and Stiles, 1989). For example, the Florida and California strawberry industries, which together produce $>90 \%$ of the nation's berries, rely extensively on preplant fumigation for control of soil diseases. Unlike much of the germplasm developed for the rest of the country, resistance to soilborne diseases was not a top priority in California strawberry breeding programs. In the major tree-fruit production centers of Washington, $85 \%$ of the apple replant sites require soil fumigation during renovation. This practice has been shown to increase yields greatly when older orchards are replanted with intensively managed, high-density systems (Smith, 1993). The ban on methyl bromide and other soil fumigants will have a severe impact on these fruit industries, and also on the international trade in fruits, which must be fumigated to prevent the spread of pests. However, continued use of methyl bromide is ill-advised because it may damage Earth's vital ozone shield.

Certain aspects of current intensive production and marketing systems are probably not sustainable in their present form, but they were developed in response to intensifying market competition and the need for greater short-term profitability. Although some modern fruit-growing techniques enhance sustainability (e.g., micropropagation, integrated pest management, virus-indexing, clonal rootstocks), most have increased grower reliance on purchased inputs. Today's fruit production thus approaches the goals of sustainability in some respects, but it is seriously lacking in others, such as the narrow genetic base of existing plantings and the need for soil treatment with broad-spectrum biocides to maintain production in continuous monocultures.

\section{Sustainability issues in hit production}

Resource conservation and availability. For conservation of soil and water resources, growing perennial fruits offers many advantages when compared with agronomic crops. Fruit trees, vines, and bushes can provide excellent protection for the soil because the persistent roots, leaf litter, and surface cover crops beneath woody plants improve soil structure, nutrient, and water retention. These benefits are especially important for hillside farms, which are ill-suited to tillage and annual crops. Fruit growing and agroforestry systems are thus widely recommended for fragile soils and flood-prone watersheds (Steppler and Lundgren, 1988). Fruit plantings also can provide a relatively rich habitat for both plant and animal species (including pests), with a variety of niches allowing for greater species diversity than many other agroecosystems. This habitat diversity complicates pest management because it pro- 
vides many sites for pests such as mites, codling moth, or fruit flies to overwinter or elude natural predators (Croft and Hoyt, 1983). Fortunately, such complex habitats are potentially more suitable for establishing beneficial flora and fauna that might provide biological control of economic pests within integrated pest management (IPM) programs. As pheromone baits and mating disruption techniques are improved, the structural complexity of orchards also should enhance the effectiveness and stability of these low-chemical-input control tactics.

While much is made of soil and water resource limitations, the availability of land or water for fruit growing may be jeopardized more by urban and suburban sprawl than by any direct impacts of conventional farming practices on natural resources. In many prime fruit-growing regions, such as California's Central Valley, growers must compete with industrial, commercial, and residential real estate development for increasingly scarce land and water (Carter et al., 1991). More than $70 \%$ of the fruit crop acreage in the United States is irrigated and, in the Southwest, nearly $75 \%$ of that irrigated acreage relies on declining groundwater reserves (NRC, 1989). Conversion from flood or sprinkler irrigation to more-efficient drip- or sub-irrigation systems may reduce the urban/rural competition for water in arid areas, but, in the present economy, agricultural land usage rarely will preempt commercial or residential development. Growers themselves often oppose protective measures, such as conservation easements or restrictive agricultural zoning, which might deprive them of the lucrative option of selling-out to developers. Once again, we encounter a situation in which a farming system itself may be sustainable, but it is unable to withstand pressures from socioeconomic trends external to the agroecosystem.

Fruit farms as national cultural heritage. Fruit plantings are considered by many people to be an aesthetically pleasing part of the rural landscape. In this sense, fruitgrowing regions actually can be viewed as part of the national heritage-a managed natural resource worthy of preservation. This attitude is especially prevalent in Europe, where the famous wine-grape regions are managed almost like a scenic park system. It often is noted that $<3 \%$ of the population in the United States is now employed in agriculture, and that the political constituency that supported the family farm has disappeared from our contemporary urban culture. This need not mean the end of public appreciation and support for fruit growing and agriculture as essential aspects of the human cultural heritage. Orchards and vineyards in many parts of Europe and the United States are popular tourist attractions. Much of the berry crop production in the Northeast and Midwest is marketed as "pick-your-own." Urban people still can appreciate the beauty of intensively managed landscapes, and enjoy their ciders, wines, autumn foliage, and fruit harvest traditions. In these aspects, fruit growing represents the harmonious, long-term integration of agriculture and human civilization with the natural environment. Fruits themselves are powerful symbols in many religions and cultures, but this commonality between fruit growers and the general populace has been forgotten or under-used, especially in the United States. Fruit growers should pay more attention to these cultural issues in order to maintain public trust and support. They will not succeed by managing their farms like factories in the field, or presenting their fruit to the public as if it were just another commodity.

Agrichemical inputs in fruit production. Perhaps the greatest perceived threat to the sustainability of modern fruit production is its extensive reliance on synthetic pesticides and fertilizers. Fruit growing often serves as a convenient scapegoat for chemicalintensive, high-input agriculture, which is portrayed as exploiting and endangering farmworkers, wildlife, and natural resources (Edwards, 1993). Unquestionably, modern fruit production systems involve relatively high inputs of pesticides per unit of production. Market and regulatory forces discourage agrichemical usage, but also mandate blemish-free fruit. Is the chemical-intensive, bad-for-the-environment reputation of modern fruit growing really justified by the facts? In some comparisons with agronomic crops, fruit growing actually appears more sustainable. For instance, inputs of the herbicides and fertilizers implicated in water pollution are usually lower in fruit production than in field crops (USDA, 1992). This is attributed to the protection of topsoil, use of cover crops, and recycling of nutrients in perennial crop systems. The ratio of energy inputs to crop outputs is higher in fruits than in field crops, but the much greater market value per unit output makes fruits more efficient when energy input costs per crop output value are compared (Pimentel, 1979). It obviously would be impractical to apply $\$ 375$ worth of pesticides (about average for apples in the eastern United States) on an acre of grain for which the harvest may only be worth $\$ 250$. However, \$375 is a minimal input compared to the $\$ 10,000$-per-acre value of fresh-market apples or $\$ 40,000$-per-acre value for strawberries.

Pesticide usage per acre of fruit production is greater than in most other crop sys-
"Is the

chemical-

intensive, bad-

for-the-

environment

reputation of

modern fruit

growing really

justified by the

facts?" 
'F $\boldsymbol{F}_{\text {ruit growing }}$

accounts for an

insignificant

part of total her-

bicide usage be-

cause the acreage

planted to fruit is

very small com-

pared to corn,

wheat, or soy-

beans, and

because the soil

surface in many

perennial fruit

plantings is

maintained in

grass or seasonal

cover crops." tems, but substantial reductions in gross applications and dose-equivalents of pesticide have been documented recently with the adoption of IPM and nonpesticidal biocontrol practices (Osteen, 1993). Much of the increase in aggregate pesticide use during the past 40 years has consisted of herbicides. Fruit growing accounts for an insignificant part of total herbicide usage because the acreage planted to fruit is very small compared to corn, wheat, or soybeans, and because the soil surface in many perennial fruit plantings is maintained in grass or seasonal cover crops. For these reasons, the extensive environmental benefits of a minor pesticide use reduction in field crop production would be potentially much greater than that of a major reduction in fruit pesticide usage. Moreover, nonpoint source pollution of water by erosion, leaching, and surface runoff of agricultural chemicals actually has proven to be more of a problem in the Midwest Corn Belt and animal feedlots than around fruitgrowing centers (Neilsen and Lee, 1987). Therefore, the fact that pesticide inputs per acre of orchard are relatively high does not mean necessarily that agrichemical inputs in fruit growing are nonsustainable in the context of either cost/benefit ratios or environmental impacts.

Certain fruit crops have especially low agrichemical requirements, and can approach sustainability when grown appropriately. For example, some blueberry plantings have remained productive for more than 60 years with little external input beyond routine fertilization and pruning. Blueberries thrive on organic sources of nitrogen, and have very low demands for other nutrients. Pest problems (other than birds) are minimal in blueberries outside of the few major commercial production centers. A vast potential germplasm source exists in wild populations throughout North America, and these are being used to improve available varieties. Other examples of particular crops or varieties that can be grown successfully with minimal reliance on purchased chemical inputs include new and old varieties of diseaseresistant apples, native American grapes, primocane-fruiting raspberries, and native fruits such as the pawpaw. In the future, growers may rely more upon these pestresistant varieties and indigenous fruits.

Public apprehension about agrichemicals has increased greatly the regulatory impediments and costs of developing and marketing new pesticides. Increased costs and stricter regulations, coupled with the rapid development of biochemical resistance to pesticides by many fungi, insects, and weeds, has created a crisis in conventional pest control for many fruit crops. This is especially true with fungicides, of which there remain only a few effective broad-spectrum compounds (NRC, 1987). Fruit and vegetable crops account for much of the total fungicide usage in the United States. With stricter enforcement of the "Delaney Clause" zero-risk rule for pesticide residue tolerances on processed foods, many of the older broad-spectrum fungicides may be banned. The newer sterol-inhibitortype fungicides will not be affected immediately by this ruling. However, these narrowspectrum fungicides eventually will be overcome by resistant pest genotypes unless they are applied in combination with the older broad-spectrum pesticides several times each year. It is thus conceivable that many commercial fruit growers in the United States may soon find themselves without effective fungicides (NRC, 1987).

Unless new horticultural varieties resistant to the major fungal diseases are developed for each crop, adopted by growers, and accepted by consumers in the marketplace, fruit growing in certain regions may not be profitable in the long-term. As consumers continue to demand unblemished produce that has been grown without pesticides, fruit production in humid areas of the United States probably will comprise a smaller share of the wholesale market. Production in drier regions will be favored because disease, insect, and weed problems are usually less severe in such areas. A further shift in fruit production from eastern to western states likely will accelerate the market dominance of large, corporate-owned farms. However, for these farms in the western United States to be profitable, fossil fuels and transportation must remain cheap enough for them to supply distant markets, and water resources must remain available. Conflicts between urban, industrial, agricultural, and wildlife requirements for water will probably increase, and more fruit production might shift to countries such as Mexico and Chile.

Genetic resources in fruit production. Of the commercially grown fruit crops, only blueberries and cranberries are native exclusively to North America. Germplasm resources for other important fruit crops are located throughout the world, often in natural forests or agroecosystems that are threatened by human population pressures and land development projects. Among the fruit crops considered most at risk by the United Nations International Board for Plant Genetic Resources are apple, avocado, coconut, mango, and pear-all important commercial crops in many regions of the world. Collection and preservation of genetic materials in many different locations will be essential for the long-term sustainability of fruit production. These plant materials may contain genes 
that confer resistance to pests or environmental stress, and confer traits that improve yield and quality. Ironically, the dissemination of improved fruit cultivars is itself eroding the genetic base necessary to sustain fruit production, as these improved cultivars often replace valuable landraces at the centers of origin for a crop. For example, in a recent survey of an important center of genetic resources for avocado, Smith et al. (1992) noted that Mexican growers were top-working many of the traditional local avocado varieties, replacing them with the California 'Hass' variety, because it commands a higher price in local markets.

Germplasm repositories and collections have been established throughout the United States and the world for most of the major fruit crops, but they contain only a small fraction of the existing genetic diversity for these crops. Perennial fruits often can be hybridized successfully with many other species of the same genus. This creates enormous genetic potential for improving fruit crops, but it also requires that germplasm be preserved for many of the other cross-compatible species in addition to the crop species itself. For example, it is not sufficient to conserve the 8000 or so known apple varieties from the many centers of origin and production. Important genotypes also are likely to exist among the 35 other species of Malus that exist throughout the northern hemisphere, and these must also be collected, characterized, and protected in repositories or preferably in their natural range (Brown, 1975). Agreements and germplasm exchange among more than 100 nations will be required to prevent further extinctions of fruit crop germplasm at important centers of diversity.

Tropical fruits often have "recalcitrant" seeds without a dormant phase, and they do not survive drying or freezing. These fruits can be perpetuated only in tissue culture, or as living plants in the field. Therefore, the only truly effective way to conserve genetic resources for many of the world's fruits is to set aside large biosphere reserves or protected national parks at the centers of origin. This will require considerable forethought and international cooperation. Incentives must be provided to host countries, including acceptable alternatives for residents whose present lifestyles may conflict with genetic conservation efforts. In many regions of the Third World, shortages of cooking fuel and arable land are forcing people to cut down their ancestral groves of apples, nuts, and many other fruits. Sustainable farming in any one country is thus intimately tied to the wellbeing of other countries, and acknowledging this fact is perhaps the biggest challenge facing the sustainable farming movement.
Capital and human resources in fruit production. High costs and limited availability of capital and labor are other serious problems facing modern fruit growers. Fortunately, the relatively high market value for most fruits has offset those capital and labor inputs, and the fruit industry has remained profitable in North America and Europe without the massive government subsidies and import protection typical of many agronomic crops. Furthermore, in an era characterized by acreage conglomeration and mechanization, it is still possible for growers to make a living on $<100$ acres of good fruit-growing land. In many fruit-growing regions of North America and Europe, a substantial part of the production comes from family farms. In regions where small-scale growers have formed fruit storage and marketing cooperatives, as in the state of Washington, they have been especially successful.

In comparison with field crops, fruit production is very labor-intensive. For example, harvesting, handling, and pruning labor account for nearly $40 \%$ of total apple production costs in the eastern United States (Castaldi, 1989). Postharvest storage, processing, and transportation are also very labor-intensive for fruits. Thus, fruit growing provides more employment opportunities in rural communities than most other crops, and helps to sustain the rural employment base. However, this labor requirement also poses a problem for growers due to the scarcity of agricultural workers in many parts of Europe and the United States, and the seasonal nature of fruit production (Taylor and Thilmany, 1992). Labor supply and costs may become even more problematic if the North American Free Trade Agreement (NAFTA) brings American growers into more direct competition with other nations where labor costs are much lower, and environmental regulations are absent or inadequately enforced.

Capital costs and availability were a major problem for agriculture during the highinterest and inflationary years of the 1970s and 1980s. Although interest rates now have declined, many banks are still hesitant to extend credit to farmers. Economic surveys indicate that about $70 \%$ of fruit growers in the United States are presently in a "favorable" financial condition (positive income and solvent), while $12 \%$ are in "marginal" or "vulnerable" financial condition (NRC, 1989). In certain regions of the United States, the proportion of growers in financial difficulties is much greater. Fruit growers generally have fared better than other farmers during recent decades, although wholesale prices for fruits have increased less than costs of production (How, 1991).
“. . . in an era characterized by acreage conglomeration and mechanization, it is still possible

for growers to make a living on $<100$ acres of good fruitgrowing land." 


\section{New paradigms in horticulture}

Process vs. product. Few would disagree that federal support for applied agricultural research and extension has contributed substantially to our present surplus of fruits and other foods. Ironically, those surpluses are now contributing to the demise offederal support for such programs. A century of emphasis on increasing yield per unit of land and labor appears to be giving way to a fundamentally different priority-decreasing the external inputs and environmental impacts of food and fiber production systems, even if this results in reduced productivity. The new agricultural paradigm is holistic, emphasizing process as well as product, and quality more than quantity.

As might be expected, there is little agreement within the agricultural community on the necessity or desirability of this paradigm shift. The National Academy of Sciences (NRC, 1989) has asserted that we can and should make the transition to selfsustaining systems without undermining the present affordable food supply. The Council for Agricultural Science and Technology (CAST, 1990) has countered that our present food surplus is ephemeral in the face of world population increases, and that we must maintain crop productivity above the intrinsic "carrying capacity" or internally sustainable output of most agroecosystems in order to avoid serious food shortages. The essential difference between these two views rests on differing estimates of the long-term productivity of conventional vs. alternative systems. It is difficult to reconcile these two contrasting views, but at least the current food surplus allows horticulturists the opportunity to consider systems that trade-off a certain amount of yield in favor of reduced energy requirements and/or environmental impacts. There is still time to develop alternatives, and the public pressure for such changes is increasingly urgent.

Self-sufficiency vs. government subsidies. With $80 \%$ of the American population living in urban regions and surplus reserves accumulating for most food crops, public awareness about agriculture and support for government crop subsidies have vanished. Direct payments to farmers are targeted for sweeping cuts at the federal level. However, many "hidden" government subsidies continue, in particular those that maintain artificially low energy costs in the United States. Hidden energy subsidies include programs such as federal leasing of oil fields at below cost, military defense of international oil reserves and shipping, or federally funded clean- up of accidental spills. These subsidies tend to perpetuate the inefficient use of energy by the general public, as well as wasteful farming practices, such as overuse of synthetic fertilizers or continued pumping of depleted groundwater sources. They prolong inefficient practices that would become nonsustainable if their true costs were collected from growers and/or reflected in the market value of food and fiber (Hubbard, 1991). Indirect energy subsidies to agriculture probably will diminish in the future as fossil fuel resources are depleted and "greenhouse" gases become increasingly problematic. It remains to be seen whether governments will take appropriate actions to bring market prices more in line with the true costs of food production.

Systems science vs. disciplinary science. In an era in which major scientific breakthroughs are widely heralded, it must be remembered that there are fundamental limits to the long-term productive capacity of every agroecosystem, even provided with unlimited external resource inputs. Much of the recent research in fruit production systems has been based on the physiological assumption that the only fundamental limitation to crop production is the efficiency of light capture by photosynthetic systems and the plant canopy. Molecular biologists have taken this assumption one step further, and are attempting to augment genetically the synthesis or catalytic efficiencies of important enzymes in crop plants. Federal agencies now are diverting funds from applied programs to support such basic research under yet another assumption-that it will provide practical benefits to agriculture in the near future. Are these assumptions consistent with the basic principles of ecosystem biology relating to agriculture?

Agroecologists point out that maintaining nutrient and water inputs at such high levels that only the availability of sunlight limits plant growth or yield is likely to result in excessive leaching of agrichemicals and contamination of groundwater resources needed to sustain the crop system, the rural community, and wildlife (Soule et al., 1990). Also, the high tissue nitrogen concentrations necessary to maintain nonlimiting chlorophyll or leaf area usually make the crop more vulnerable to a number of pests and diseases, thereby requiring increased pesticide inputs to protect the crop and accelerating the selection of resistant pest biotypes. There are a number ofmechanisms through which excessive energy, agrichemical, or water inputs to an agroecosystem eventually can undermine its productivity or that of related ecosystems-for example, soil salinization, atmospheric pollution, or fisheries depletion by water diversion to irrigation. It will not be 
possible to improve perpetually the productivity of agroecosystems without eventually causing significant negative impacts on vital natural resources or other interdependent systems. Therefore, sustainable solutions to humanity's long-term food requirements will not be found by concentrating solely on the physiological or biochemical components of crop systems and neglecting their underlying ecological principles.

Will new biotechnologies fundamentally change the way fruits are grown? Genetic engineering is a powerful tool for moving single genes from one organism to another, conferring traits such as herbicide resistance, virus resistance, or delayed ripening of fruits such as tomatoes. However, many of the genes that determine such traits have not been mapped or located in the genome for fruit crops, which are often highly heterozygous because they are genetically self-incompatible and polyploid. Moreover, the major biological components of crop productionsuch as growth habit, yield, or harvest index-involve complex traits that are not yet amenable to genetic manipulationin the laboratory. Biotechnology may reduce the time required to achieve certain limited goals, but it is unlikely to cause fundamental qualitative changes in fruit production in the near future. Advances probably will occur first in agronomic crops, with practical applications to fruit production lagging far behind in proportion to the amount of basic research and development focused on fruits. A final unanswered, but important, question is whether consumers will accept genetically engineered produce, especially foods such as fruits with special cultural and symbolic importance.

Moderating demand vs. increasing supply. Can we reasonably hope that the present rates of human population increase will decline before the ultimate ecological carrying capacity of the world's farmland is confronted or eroded? If so, then we could make a strong case that horticulturists must stretch food production systems beyond sustainable limits during coming decades as a stop-gap effort to overcome the last demographic hurdles of development. There is ample evidence that once nations achieve a standard of living with low infant mortality and care for the sick and elderly, birth rates usually level off and approach zero-population growth. However, recent studies show that standards of living and per-capita food production actually are now declining in much of the Third World (WRI, 1992). Another recent CAST report (1992) typifies the optimistic belief that new biotechnologies will revolutionize agriculture and enable us to increase food production in time to provide for the world's population, assuming no ma- jor climate disruptions caused by atmospheric pollution. Although these new technologies can have many positive impacts, it is unlikely that they will soon bring about major changes in production practices, especially in countries where land and food are already scarce or unaffordable for millions of people.

\section{Summary}

The demand for fruit is driven by consumers who want to increase the quality and variety of their diet. As countries develop, their demand for fruit increases greatly and the traditional home gardens or natural groves that previously supplied them with fruit often are lost to urbanization, deforestation, or replacement by monocultures. Fruit consumption has increased steadily in the industrialized nations, especially with recent reports establishing the importance of fresh fruits for cancer prevention and human health. Demand for fruit is increasing, but land suitable for fruit growing is in short supply in much of the world. This situation has led to an increase in external inputs to increase fruit production per unit of land. Some of the consequences of these changes-environmental degradation, distressed rural communities, and resource depletion-now are being scrutinized by a public that wants qualitative improvements in the way fruit is produced, without diminishing the quantities presently available. Unfortunately, neither the people nor their governments usually comprehend the complexities of agriculture. Individuals who demand pesticide-free production systems also insist on blemish-free fruit. Those who are concerned about the plight of migrant farmworkers and the family farm also expect to pay low food prices, which makes it difficult for growers to pay adequate wages. Many who are upset at the loss of small farms in the United States fail to support their own local farmers.

Growers are being urged to adopt practices that may reduce crop production and profitability in order to assure sustainability in the next century, but they must operate within the economic and political constraints established by society. Sustainability cannot be achieved without changes in society as well as agriculture. The real, direct, and indirect costs of agrichemical use and other farming practices eventually will be paid by growers one way or another, and the full value of national resources such as water and topsoil must be included in that assessment. Conversely, consumers in the developed world must be willing to pay more for fruit and other foods, to enable farmers to survive and prosper within the new environmental constraints. People must alter their dietary and

\section{${ }^{\mathbf{S}} \boldsymbol{S}_{\text {ustainability }}$ cannot be achieved without changes in society as well as agriculture."}


shopping habits in ways that help support local growers and rural communities. Governments must regulate farming objectively, weighing risks and benefits, while focusing on the major impacts of agricultural policies and practices.

Because most of the germplasm resources for major crops are found outside of North America, international agreements and incentives must be established to help preserve the forests, farmlands, and the human cultures where these genetic treasures are located. Unprecedented cooperation among land-grant universities, government, and the media will be required to educate the public about agriculture, and promote a society where sustainable farming is truly rewarded. Fruit crop production may provide an ideal model and forum to demonstrate how sustainable systems can be developed and preserved.

\section{Literature Cited}

Brown, A.G. 1975. Apples, p. 3-37. In: J. Janick and J.N. Moore (eds.). Advances in fruit breeding Purdue Univ. Press, West Lafayette, Ind.

Carter, H.O., R. Coppoci, L. Kennedy, C. Nuckton, and J. Spezia. 1991. Keeping the valley green: A public policy change. Calif. Agr. 45(3):10-14.

Council for Agricultural Science and Technology. 1990. Alternative agriculture-scientists review. CAST, Ames, Iowa.

Council for Agricultural Science and Technology. 1992. Preparing U.S. agriculture for global climate change. CAST, Ames, Iowa.

Castaldi, M. 1989. A survey of the cost of growing and harvesting apples in eastern New York in 1988. Cornell Univ. Coop Ext. Bul. XB016.

Crews, T.E., C.L. Mohler, and A. G. Power. 1992. Energetics and ecosystem integrity: The defining principles of sustainable agriculture. Amer. J. Alt. Agr. 6:146-149.

Croft, B.A. and S.C. Hoyt. 1983. Integrated management of insect pests of pome and stone fruits. Wiley, New York.

Edwards, C.A. 1993. The impact of pesticides on the environment, p. 13-46. In: D. Pimentel and H. Lehman (eds.). The pesticide question. Chapman and Hall, New York.

How, R.R. 1991. Marketing fresh fruits and vegetables. AVI, New York.

Hubbard, H. 1991. The real cost of energy. Scientific Amer. 264(4):36-42.
Mai, W.F. and G.S. Abawi. 1981. Controlling replant diseases of pome and stone fruits in northeastern United States by preplant fumigation. Plant Dis. 65:859-864.

Merwin, I.A. and W.C. Stiles. 1989. Root-lesion nematodes, potassium deficiency, and prior cover crops as factors in apple replant disease. J. Amer. Soc. Hort. Sci. 114:724-728.

Neilsen, E.G. and L.K. Lee. 1987. The magnitude and costs of groundwater contamination from agricultural chemicals. Economic Research Service, USDA, Staff. Rpt. AGES87.

National Research Council. 1987. Regulating pesticides in food: The Delaney paradox. National Academy Press, Washington, D.C.

National Research Council. 1989. Alternative Agriculture. National Academy Press, Washington, D.C.

Osteen, C. 1993. Pesticide use, trends and issues in the United States, p. 307-336. In: D. Pimentel and H. Lehman (eds.). The pesticide question. Chapman and Hall, New York.

Pimentel, D., and M. Pimentel. 1979. Food, energy and society. Edward Arnold, New York.

Simmonds, N.W. 1976. Evolution of crop plants. Longman, Essex, U.K.

Smith, T.J. 1993. Orchard replant disease. Good Fruit Grower, Mar. p. 35--8.

Smith, N.J.H., J.T. Williams, D.L. Plucknett, and J.P. Talbot. 1992. Tropical forests and their crops. Cornell Univ. Press, Ithaca, N.Y.

Soule, J., D. Carre, and W. Jackson. 1990. Ecological impact of modern agriculture, p. 165-188. In: C.R. Carroll et al (eds.). Agroecology, McGrawHill, New York.

Steppler, H.A. and B.O. Lundgren. 1988. Agroforestry: Now and in the future. Outlook on Agr. 17:146-152.

Taylor, J. E. and D. Thilmany. 1992. California farmers still rely on new immigrants for field labor. Calif. Agr. 46:4-6.

USDA. 1992. Agricultural chemical usage: 1991 fruits and nuts summary. USDA, NASS, ERS, Agr Ch.1(92). Govt. Printing Office, Washington. D.C.

World Resources Institute. 1992. World resources report: 1992-93. Oxford Univ., Oxford, U.K.

York, E.T., Jr. 1991. Agricultural sustainability and its implications to the horticulture profession and the ability to meet global food needs. HortScience 26:1252-1257. 